\title{
Innovative Research on Value Creation Mode of Internet-Based Crossover Operation Strategy of Traditional Enterprise
}

\author{
Na Wang, a , Suchun Fang ${ }^{2, b}$ and Wei Wang ${ }^{3, c, ~ * ~}$ \\ ${ }^{1}$ School of Management, Changchun Science and Technology University, Changchun 130600, China \\ ${ }^{2}$ Department of Human Studies, Seisen University, 720 Hida-cho, Hikone, Shiga Prefecture, Japan \\ ${ }^{3}$ Shenyang Institute of Technology, Shenyang 113122, China \\ a397365224@qq.com, b40191584@qq.com, c380156193@qq.com \\ *corresponding author
}

Keywords: Traditional enterprise, Internet, Crossover Operation Strategy, Value Creation Mode.

\begin{abstract}
With the rapid development of internet technology, traditional enterprise which is labourintensive processing and manufacturing develop slower. It becomes an inevitable choice for traditional enterprise to break the shackles, implement the strategy of crossover operation based on the internet, and to find a new mode of value creation. This paper takes traditional enterprise as the research object, bases on its current development situation and the dilemma of value creation as the research present situation. The value create model based on the internet crossover operation strategy is proposed so that traditional enterprise can be out of the plight, and help traditional enterprise achieve the transformation of development.
\end{abstract}

\section{The traditional model of enterprise value creation and their plight}

Enterprise value creation model refers to a model of effective value creation of enterprise, which takes value maximization as the goal, combines resource and ability of enterprise and organizes value creation activities through economic management means, in order to realize the whole value creation process. Traditional model of enterprise value creation is numerous, although different scholars' points of view of the value creation patterns vary. In general, the value chain model proposed by Michael porter is more applied. It illustrates the type of value activities and reveals its relationship with the profits. Most of the traditional enterprise value creation activities are in internal production and sales link and directly create value for the enterprise.

In recent years, essence change has taken place in consumer access to information, behavior and consumption habits due to the rapid development of internet, especially the rapid rise of the mobile internet. According to CNNIC published in July 2016, the $38^{\text {th }}<$ the China internet development statistics report> shows the number of Chinese internet users reached 710 million, mobile phone network user 656 million, nearly 200 million rural users. By June 2016, the Chinese site number 4.54 million. It shows that the internet penetration rate is very high in our country. Among them mobile internet shows its dominance and strong momentum of development. While the traditional enterprise unable to adapt to the new market environment, its development is slower. The lack of ability to adapt mainly includes:

\subsection{Lack in understanding electronic commerce}

Traditional enterprise simply takes the e-commerce as the internet sales, it won't have too much impact on the traditional enterprise, instead of its changing the whole traditional supply chain. And on the internet, companies need more is the terminal consumer demand as the guidance of the sales process, that is, e-commerce can production and sales, you can even use a design draft for sales, such as booking on some famous online store of Taobao.com. 


\subsection{Focusing on advertising instead of experience utility}

Traditional enterprises are accustomed to use high density and mass media advertising, but the internet age, information transfer is fast without barriers, businesses and consumers are almost equal in access to information, enterprise value cannot be improved by traditional advertising, while experiential marketing is the main force in the internet age. Such as the "shiyong.com" founded in 2006, is a free platform for user to trial product, which has hundreds of registered users in just two months. Users in the tested product or service must be submitted after the trial result, obtain market and customer data for the manufacturer. Its main income comes from the manufacturer. Its characteristic is "try" and "experience", these two features have a great influence to the Chinese psychology, also is the key to the development of it.

\subsection{Loss efficiency of traditional mode}

The point of traditional mode of enterprise value creation is to reduce cost, but for now operating costs have become so low that it cannot be further lowered. The corresponding strategy of the internet, however, has more timeliness, broad audience, especially the digital technology to optimize the customer relationship, increased the convenience of customers. At the same time, companies also can analyze the huge amounts of data obtained via the internet, and then observe the user behavior, adjust the goods or services at the same time, to get more valuable before reaching the customer. Traditional enterprise value model does seem lack of efficiency in the face of such impact.

\section{Internet-based crossover operation strategy}

Crossover operation is a relatively new term; often appear at news headlines, such as: crossborder cooperation, cross-border marketing and so on. The definitions and related data of crossover operation can be collected in the literature and very few in numbers. Although cross-border management theory is not much, but it is very wide application in practical, and even has become one of the most common enterprise management paradigm.

About the defining of internet crossover operation strategy, there are no scholars put forward a clear definition, only some successful experience in the enterprise practice. After analyzing, sorting and induction, here is its definition. internet crossover operation strategy refers to the enterprises break through the boundaries of the original management field, relying on the internet platform, combine the internet and traditional enterprise management field, use existing resources and the internet resources as a whole, and to find and create a new multidimensional value growth on the enterprise value chain, seek the further development of the enterprise. Internet crossover operation strategy means to break the traditional enterprise strategic management model, get rid of the shackles of existing management field and bondage, seek to work closely with internet resources, and thus it can achieve a synergistic effect, create value for the enterprise.

At present, the application of internet-based cross-border operation strategy is very much; the type of internet-based crossover operation strategy in the enterprise management practice mainly as following:

\subsection{Product/service-based internet crossover operation strategy}

Product-based internet crossover operation strategy refers to the business scope of enterprise cross-border mainly concentrated in the field of products. Such as: Kangmei pharmaceutical co., LTD. (stock code: 600518) breaks through the original main business products-traditional Chinese medicine (TCM), operates from proprietary Chinese medicine to establishing electric business platform about Chinese medicine resources, looking for value creation in the new electricity field, become Chinese medicine enterprise cross-border electricity rookie. This is implemented of internet crossover operation strategy based on the product/service. 


\subsection{Marketing-based internet crossover operation strategy}

Internet crossover operation strategy based on marketing refers to the enterprise whose internet cross-border business scope mainly concentrated in the field of marketing; the specific sales crossover operates from the way of publicity, promotion, channel, etc. As advertising "drink Mengniu and win a Didi taxi red envelope", it seems to be a flash in the WeChat refresh the circle of friends. Mengniu and Didi taxi, one is extremely having the market appeal of dairy brand, one has daily orders for more than 5 million mobile travel information platforms, and has the number of users of more than 100 million, they achieved a $1+1>2$ integration effect at marketing crossborder.

\section{New mode of value creation based on the internet crossover operation strategy}

The new mode of value creation of internet-based crossover operation strategy is a mode that can integrate the traditional enterprise value chain activities with internet resources. The central idea is to use the internet platform, information and communication technology, combined with traditional value chain of enterprise. Thus, the advantage of the internet resources can improve enterprise's value creation.

\subsection{The orientation of maximizing value based on internet thinking strategy}

Internet has made great changes have taken place in the carrier of value creation. In the traditional economy, the carrier of value creation is the value chain proposed strategy management master Michael porter, while in the internet economy the carrier of the value creation is network platform. Relative to the traditional value chain linear thinking, network platform is more important is to consider the dynamic economic activity, virtual operating activities, etc. value creation mode based on cross-border has characteristics of dynamic economy and virtual management, which emphasizes on enterprise value appreciation in the premise of internet.

\subsection{Enterprise value creation ability based on cross-border operation strategy}

The focus of internet crossover model is the new method of using the internet cross-border business to find new profit source and to enhance the enterprise value creation ability. China mobile and China Unicom in the mobile communications market game for a long time, suddenly found that Tencent and WeChat become the biggest winner of mobile communication. They use the internet to improve enterprise value creation ability. There are a lot of similar enterprises, Alibaba does crossborder internet finance business, Changhong sets foot in the internet industry. The deep reason of these internet crossover operation strategy is because they can improve their ability of the value creation after penetration internet, bring new profit source. Internet cross-border provides enterprises with no boundary in the field of business possibilities.

\subsection{The value creation mode based on virtual supply chain and virtual value chain}

Internet cross-border business model is based on virtual supply chain and virtual value chain; it is the premise of all across borders value activities, including cross-border network procurement, across borders network manufacturing, network marketing etc. Enterprise can obtain produce efficiency through these kinds of crossover. Different from those traditional industrial chains of vertical and horizontal integration, crossover is through virtual integrating across the border from the traditional industry, which can produce synergistic effect through the cooperation relationship between industries and economies of scope and so on. Because of the virtual value chain and the supply chain, manufacturers can save huge costs of traditional advertising. They can even build electric business platform, logistics platform, breakthrough traditional boundaries in the channel, to take direct marketing, reduce the cost of circulation, unify the value stream, information flow, and cash flow. 


\section{Conclusion}

This article mainly analyzes the traditional model of enterprise value creation and their plight, traditional enterprise's value creation model is generally based on value chain activities. Under the internet economy, traditional enterprise has been difficult to development merely relying on internal value chain optimization. They might make the enterprise to adapt to the external economic environment to development if they combine with the internet and implement the internet crossover operation strategy. Based on the application practice of cross-border business in the actual situation of enterprise management, through many researches, the meaning of internet crossover operation strategy was first defined here; it also analyzes several types commonly used in the enterprise practice. Furthermore, a new value creation pattern is proposed which based on the internet crossover operation strategy, namely the new mode of integrating the traditional enterprise value chain activities with internet resources.

\section{Acknowledgments}

This work was supported by Chunhui project of China's ministry of education 2015. Project approval no.: S2015012

\section{References}

[1]. Tian Liu, Xie Hui. Enterprise value creation model research, accounting communication [J], 2015, 26

[2]. Haijian Li, Feng Li. Source and enterprise value theory research [J], China's industrial economy, 2004 (3)

[3]. Qingjun Luo, Potter's value chain model of the painting and its explanation [J], business studies, 10th, 2002

[4]. Ding Yonggan, Xiaofeng Shen. Enterprise value driving factors and value creation mode, accounting, 32, 2015

[5]. Li Changhong, Xie Yuanyuan. Intellectual capital based on the strategic alliance of enterprise value creation [J], east China economic management, 2011, 25 (2) 